\author{
A.R. Yeshkeyev ${ }^{*}$, A.K. Issayeva, N.K. Shamatayeva \\ Karagandy university of the name of academician E.A. Buketov, Karaganda, Kazakhstan \\ (E-mail: aibat.kz@gmail.com, isaaiga13@gmail.com,naz.kz85@mail.ru)
}

\title{
On atomic and algebraically prime models obtained by closure of definable sets
}

\begin{abstract}
This article discusses the properties of atomic and prime models obtained with the some closure operator given on definable subsets of the semantic model some fixed Jonsson theory. The main result is to obtain the equivalence of the thus defined atomic and prime models, and this coincidence follows the assumption that there is some model with nice-defined properties.
\end{abstract}

Keywords: Jonsson theory, semantic model, prime model, atomic model, algebraically prime model, pregeometry, definable subset.

The paper considered the syntactic and semantic characteristics of prime and atomic models [1]. A. Robinson defined a natural generalization of a prime model, and he called such a model an algebraically prime model. In work [2] the corresponding notions of atomicity and their connection with an algebraically prime model were systematically studied. We propose several new types of atomic models and refine these concepts for algebraically prime models within the framework of these types of atomic. We have previously obtained some results in connection with these new concepts in works [3-6].

With these concepts of types of atomic and primary models we can work in fixed classes of Jonsson theories, depending on the conditions of the problem under consideration. In work [7] generalizations of the concept of isomorphic embedding were considered and within the framework of this definition results were obtained connecting the concepts of atomic and algebraically prime within the framework of this generalization. Thus, this work is a synthesis of new results obtained using ideas and concepts of works [3-6] and [7]. In [8-13] some new directions related to the study of Jonsson theories and their companions were considered and studied. The results of this work can be useful for studying the properties of countable models related to the above topics from the list of papers [3-6], [8-13].

Remind some concepts from [7].

Let $\alpha \leq \omega, \mathfrak{A}, \mathfrak{B}$ are models first order of $L$. Then the mapping $f: \mathfrak{A} \rightarrow \mathfrak{B}$ is called $\alpha$ an embedding if for any formula $\varphi(\bar{x}) \in \Pi_{\alpha}$ and any tuple $\bar{a} \in A$ from the fact that $\mathfrak{A} \models \varphi(\bar{a})$, it follows $\mathfrak{B} \models \varphi(f(\bar{a}))$. A model $\mathfrak{A}$ of the theory $T$ is called $\alpha$-algebraically prime if $\mathfrak{A} \alpha$-embeddable into any model of the theory $T$.

From the above definitions it is easy to see that the concepts of an algebraically prime model and a prime model are obtained from the concept of an $\alpha$-algebraically prime models for $\alpha=0$ and $\alpha=\omega$ respectively. If $\Gamma$ is a set of formulas, then we put $\Gamma^{*} \rightleftharpoons\{\neg \varphi / \varphi \in \Gamma\}$. If $\bar{a}=<a_{0} \ldots a_{n}>, \mathfrak{A}$ is a model, then $\bar{a} \in \mathfrak{A}$ means that $a_{i} \in A, i<n$. A type $p$ is called a $\Gamma$-type if $p \subseteq \Gamma$. Further, $t_{\Gamma}^{\mathfrak{A}}(\bar{a}) \rightleftharpoons\{\varphi(\bar{x}) / \varphi(\bar{x}) \in L, \mathfrak{A} \models \varphi(\bar{a})\}$ is called a $\Gamma$-type $\bar{a}$ in $\mathfrak{A}$. $\Gamma_{2}$-type $p$ is called a $\Gamma_{1}$-the main type if there is a $\Gamma_{1}$ is formula $\varphi(\bar{x})$ such that $T \models \forall(\bar{x})(\varphi(\bar{x}) \rightarrow \psi(\bar{x}))$ forall $\psi(\bar{x}) \in p$. In this case $\varphi(\bar{x})$ is said to generate $p$.

It is easy to see the following fact. Let $\mathfrak{A}$ is a model of the theory $T$, then $\mathfrak{A}$ is $\left(\Gamma_{1}, \Gamma_{2}\right)$-atomic model $T$ if and only if for any $\bar{a} \in A$ there is such a formula $\varphi(\bar{x}) \in \Gamma_{1}$, which is true:

a) $\mathfrak{A} \models \varphi(\bar{x})$;

b) $\varphi(\bar{x})$ generates $t_{\Gamma \cup \Gamma^{*}}^{\mathfrak{A}}(\bar{a})$.

Similarly, if $\mathfrak{A} \models T$, then $\mathfrak{A}$ is weakly $\left(\Gamma_{1}, \Gamma_{2}\right)$ atomic model of $T$ if and only if for any $\bar{a} \in A$ there is a formula $\varphi(\bar{x}) \in \Gamma_{1}$ that is true:

a) $\mathfrak{A} \models \varphi(\bar{x})$;

b) $\varphi(\bar{x})$ generates $t_{\Gamma_{2}}^{\mathfrak{A}}(\bar{a})$.

In papers [3-6] the properties of atomic models were considered with the help of the closure operator specifying some pregeometry on subsets of the semantic model of a fixed Jonsson theory.

\footnotetext{
*Corresponding author.

E-mail: aibat.kz@gmail.com
} 
Let $\mathrm{cl}$ is some closure operator defining a pregeometry over $C$ (for example $\mathrm{cl}=\mathrm{acl}$ or $\mathrm{cl}=\mathrm{dcl}$ ). It is clear that such operator is a special case of the closure operator and its example is a closure operator defined on any linear space as a linear shell. Further, the concepts under consideration are produced within the framework of a perfect Jonsson theory and if the contrary is not specified then the considered Jonsson theories are assumed to be complete for existential sentences.

Let us give definitions related to the atomic and prime model considered in this theory.

Definition 1. A set $A$ will be called the $\left(\Gamma_{1}, \Gamma_{2}\right)$-cl atomic in $T$ if:

1) $\forall \bar{a} \in A, \exists \varphi(\bar{x}) \in \Gamma_{1}$ such that $\mathfrak{A} \models \varphi(\bar{a})$;

2) $\varphi(\bar{x})$ generates $t_{\Gamma \cup \Gamma^{*}}^{\mathfrak{A}}(\bar{a})$;

3) $\operatorname{cl}(A)=M, M \in E_{T}$, where $E_{T}$ class of existentially closed models of the theory $T$;

and obtained model $M$ is said to be the $\left(\Gamma_{1}, \Gamma_{2}\right)$-cl atomic model of the theory $T$.

Definition 2. A set $A$ is said to be weakly the $\left(\Gamma_{1}, \Gamma_{2}\right)$-cl atomic in $T$, if $\forall \bar{a} \in A \exists \varphi(\bar{x}) \in \Gamma_{1}$ such that:

1) $\varphi(\bar{x}) \cup T$ is consistent;

2) $\varphi(\bar{x})$ generates $t_{\Gamma_{2} \cup \Gamma_{2}^{*}}^{\mathfrak{A}}(\bar{a})$;

3) $\operatorname{cl}(A)=M, M \in E_{T}$, where $E_{T}$ class of existentially closed models of the theory $T$; And obtained model $M$ is said to be weakly $\left(\Gamma_{1}, \Gamma_{2}\right)$-cl atomic model of the theory $T$.

Definition 3. A set $A$ is said to be almost-weakly $\left(\Gamma_{1}, \Gamma_{2}\right)$-cl atomic in $T$ if for any $\bar{a} \in A$ there exists a formula $\varphi(\bar{x}) \in \Gamma_{1}$ such that:

1) $\varphi(\bar{x}) \cup T$ is consistent;

2) $\varphi(\bar{x})$ generates $t_{\Gamma_{2}}^{\mathfrak{A}}(\bar{a})$;

3) $\operatorname{cl}(A)=M, M \in E_{T}$, where $E_{T}$ is the class of existentially closed models of theory $T$; And obtained model $M$ is said to be almost-weakly $\left(\Gamma_{1}, \Gamma_{2}\right)$-cl atomic model of the theory $T$.

Definition 4. A set $A$ is said to be the $\left(\Gamma_{1}, \Gamma_{2}\right)$-cl algebraically prime of the theory $T$, if $c l(A)=M, M$ is $\left(\Gamma_{1}, \Gamma_{2}\right)$-cl atomic model of the theory $T, M \in E_{T} \cap A P_{T}$, where $A P_{T} \cap E_{T} \neq \varnothing$ and obtained model $M$ is said to be $\left(\Gamma_{1}, \Gamma_{2}\right)$-cl algebraically prime of the theory $T$.

Definition 5. A set $A$ is said to be almost $\left(\Gamma_{1}, \Gamma_{2}\right)$-cl algebraically prime of the theory $T$, if $\operatorname{cl}(A)=M, M$ is been almost $\left(\Gamma_{1}, \Gamma_{2}\right)$-cl atomic model of the theory $T, M \in E_{T} \cap A P_{T}$, where $A P_{T} \cap E_{T} \neq 0$ and obtained model $M$ is said to be almost the $\left(\Gamma_{1}, \Gamma_{2}\right)$-cl algebraically prime of the theory $T$.

Definition 6 . A set $A$ is said to be almost-weakly $\left(\Gamma_{1}, \Gamma_{2}\right)$-cl algebraically prime of theory $T$, if $c l(A)=M$, $M$ is been almost-weakly $\left(\Gamma_{1}, \Gamma_{2}\right)$-cl atomic model of the theory $T, M \in E_{T} \cap A P_{T}$, where $A P_{T} \cap E_{T} \neq 0$ and obtained model $M$ is said to be almost-weakly $\left(\Gamma_{1}, \Gamma_{2}\right)$-cl algebraically prime of the theory $T$.

For the convenience of expression

" $\mathfrak{A}$ is $\left(\Gamma_{1}, \Gamma_{2}\right)$-cl atomic model of the theory $T$ ";

" $\mathfrak{A}$ is weakly $\left(\Gamma_{1}, \Gamma_{2}\right)$-cl atomic model of theory $T$ ";

" $\mathfrak{A}$ is an almost $\left(\Gamma_{1}, \Gamma_{2}\right)$-cl atomic model of theory $T$ ";

" $\mathfrak{A}$ is an almost-weakly $\left(\Gamma_{1}, \Gamma_{2}\right)$-cl atomic model of theory $T$ "; and denote by (1), (2), (3), (4), respectively.

Lemma 1.

1. If $\left(\Gamma_{2}=\Gamma_{2}^{*}\right)$, then (1) $\Leftrightarrow(2),(3) \Leftrightarrow(4)$.

2. If $\left(\Gamma_{1}^{*} \subset \Gamma_{2}\right)$, then $(1) \Leftrightarrow(3),(2) \Leftrightarrow(4)$.

3. If $\left(\Gamma_{2} \cup \Gamma_{2}^{*}\right) \subset \Gamma_{3}$, then if

a) $\mathfrak{A}$ is weakly $\left(\Gamma_{1}, \Gamma_{2}\right)$-cl atomic model of the theory $T$, then it is true (1);

b) $\mathfrak{A}$ is an almost-weakly $\left(\Gamma_{1}, \Gamma_{2}\right)$-cl atomic model of the theory $T$, then it is true $(3)$.

4. If $\left(\Gamma_{1}^{*} \subset \Gamma_{2} \subset \Gamma_{2}^{*}\right)$, then $(1) \Leftrightarrow(2) \Leftrightarrow(3) \Leftrightarrow(4)$.

5. If $\left(\Gamma_{1}=\Gamma_{2}=\Gamma_{2}^{*}\right)$, then $(1) \Leftrightarrow(2) \Leftrightarrow(3) \Leftrightarrow(4)$.

6. If $\left(\Gamma_{1} \subset \Gamma_{1}^{\prime}\right),\left(\Gamma_{2} \subset \Gamma_{2}^{\prime}\right)$, then $\tau-\left(\Gamma_{1}, \Gamma_{2}^{\prime}\right)$-cl atomic model of the theory $T \Rightarrow \tau-\left(\Gamma_{1}^{\prime}, \Gamma_{2}\right)$-cl atomic model of the theory $T$, where $\tau \in\{\emptyset$, weakly, almost, almost-weakly $\}$.

Proof. The proof follows easily from the definition.

Lemma 2. If $T$ is complete for $\exists \Gamma_{2}$ (i.e., if $\psi(\bar{x}) \cup T$ consistent and $\psi(\bar{x}) \in \Gamma_{2}$, then it is true that $T \models \exists \bar{x} \psi(\bar{x})$ ) and $\left(\Gamma_{1} \cup \Gamma_{1}^{*}\right) \subset \Gamma_{2}$ then it is true $(1) \Leftrightarrow(2) \Leftrightarrow(3) \Leftrightarrow(4)$.

Proof. Since $\Gamma_{1}^{*} \subset \Gamma_{2}$, then, by part 2) of Lemma 1, it suffices to show (2) $\Leftrightarrow$ (1). Let (2) $\bar{a} \in A, \mathfrak{A} \models \psi(\bar{a})$, $\psi(\bar{x}) \in \Gamma_{1}, \psi(\bar{x})$ generates $t_{\Gamma_{2}}^{\mathfrak{A}}(\bar{a})$.

Let $\neg \psi(\bar{x}) \in \Gamma_{2}^{*}$ and $\mathfrak{A} \models \neg \psi(\bar{a})$. Let us show that $T \models \psi(\bar{x}) \rightarrow \neg \varphi(\bar{x})$. 
Suppose the opposite: $T \cup\{\psi(\bar{x}) \wedge \varphi(\bar{x})\}$ consistent. Since $T$ is complete for $\exists \Gamma_{2}$, then $T \models \exists \bar{x}(\psi(\bar{x}) \wedge \varphi(\bar{x}))$. So there is $\bar{b} \in A$ such that $\mathfrak{A} \models \psi(\bar{b}) \wedge \varphi(\bar{b})$. Let $\theta(\bar{x}) \in \Gamma_{1}, \mathfrak{A} \models \theta(\bar{b})$ and $\theta(\bar{x})$ generates $t_{\Gamma_{2}}^{\mathfrak{A}}(\bar{b})$ by $(2)$. Note that $T \models \theta(\bar{x}) \wedge \varphi(\bar{x})(1)$ as well as $T \vdash \psi(\bar{x}) \wedge \neg \theta(\bar{x})(2)$.

Since $\neg \theta(\bar{x}) \in \Gamma_{1}^{*} \subset \Gamma_{2}$ it follows from $(2)$ that $\neg \theta(\bar{x}) \notin t_{\Gamma_{2}}^{\mathfrak{A}}(\bar{a})$, i.e., $\mathfrak{A}=\theta(\bar{a})$. According to (1), in this case, $\mathfrak{A} \models \varphi(\bar{a})$ must be true. Contradiction. Recall that $\triangle_{\kappa} \rightleftharpoons \Sigma_{\kappa} \cap \Pi_{\kappa}$.

Corollary 3.

1) If $\Gamma_{1}=\Gamma_{2}=\Sigma_{\omega}$, then (1) $\Leftrightarrow(2) \Leftrightarrow(3) \Leftrightarrow(4)$.

2) For any $\alpha \leq \beta \leq \omega$, if $\Gamma_{1}=\triangle, \Gamma_{2}=\Sigma, T$ is complete for $\Sigma$, then it is true $(1) \Leftrightarrow(2) \Leftrightarrow(3) \Leftrightarrow(4)$.

Proof. 1) follows from part 5) of Lemma 1;

2) from Lemma 2.

If $\Gamma \in\{\Sigma ; \Pi\}$, then $\Gamma(\mathfrak{A}, \bar{a})_{\bar{a} \in A}$ denotes the set of sentences of the form $\Gamma$ in the language $L$ that are true on $(\mathfrak{A}, \bar{a})_{\bar{a} \in A}$.

Lemma 4. If $\mathfrak{A}$ is a model of $T$, then following conditions are equivalent:

1) $\mathfrak{A}$ is $\left(\Gamma_{1}, \Gamma_{2}\right)$-cl algebraically prime of the theory $T$.

2) Every model $T$ can be enriched to the model $T \cup \Pi(\mathfrak{A}, \bar{a})_{\bar{a} \in A}$.

3) Every model $T$ can be enriched to the model $T \cup \Sigma(\mathfrak{A}, \bar{a})_{\bar{a} \in A}$.

Proof 3$) \Leftrightarrow 2) \Leftrightarrow 1$ ) obviously.

Let's show 1) $\Leftrightarrow 3)$.

Let $f: \mathfrak{A} \rightarrow \mathfrak{B}$ be isomorphic embedding $\bar{a} \in A, \varphi(\bar{x}) \in \Sigma_{1}: \mathfrak{A} \models \varphi(\bar{a}), \varphi(\bar{x})=\exists \bar{y} \psi(\bar{y}, \bar{x}), \psi(\bar{y}, \bar{x}) \in \Pi$, $\overline{a_{1}} \in A, \mathfrak{A}=\psi\left(\overline{a_{1}}, \bar{a}\right)$. Then $\mathfrak{B} \models \psi\left(f\left(\overline{a_{1}}\right), f(\bar{a})\right)$ due to the fact $f$ is an isomorphic embedding.

Further, we have $\mathfrak{B}=\exists y \psi(\bar{y}, f(\bar{a}))$ i.e., $\mathfrak{B}=\varphi(f(\bar{a}))$. Hence $(\mathfrak{B}, f(\bar{a}))_{\bar{a} \in A}$ are the model of $T \cup \Sigma_{1}(\mathfrak{A}, \bar{a})_{\bar{a} \in A}$

Definition 7. Let $\Phi\left(x_{1} \ldots x_{\kappa}\right)$ be some set of formulas of the language $L$ from variables $x_{1} \ldots x_{\kappa}$. We say that $\Gamma_{1}$ locally omitted $\Phi$ if for any formula consistent with $T$ formulas $\varphi\left(x_{1} \ldots x_{\kappa}\right) \in \Gamma_{1}$ there is such a formula $\theta\left(x_{1} \ldots x_{\kappa}\right) \in \Phi$ such that $\varphi \wedge \neg \theta$ consistent with $T$.

Theorem 5. Let $T$ be $\Pi_{2}$-axiomatizable consistent theory of a countable language $L$ and for any $n<\omega$ let $\Phi\left(x_{1} \ldots x_{m_{n}}\right)$ be the set of the $\Pi_{1}$ are formulas of $m_{n}$ variables. If $T \Sigma_{1}$ locally omitted every $\Phi^{n}, n<\omega$, then $T$ has a countable model which omitted every set $\Phi^{n}, n<\omega$.

The proof can be taken from [15].

Theorem 6 . Let $T$ be a perfect Jonsson theory complete for $\Pi_{2}$ sentences. Then every $(\Sigma, \Sigma)$-cl algebraically prime model of theory $T$ is an almost-weakly $(\Sigma, \Sigma)$-cl atomic model of the theory $T$.

Proof. Let $\mathfrak{A}$ be the $(\Sigma, \Sigma)$-cl algebraically prime model of theory $T$. Suppose there is a $\bar{a} \in A$, such that $t_{\Sigma}^{\mathfrak{A}}(\bar{a})$ is not be the $\Sigma_{2}$ is principle type. Since $\Sigma_{1} \subset \Pi_{2}$ then by Theorem 5 , there exists a model $\mathfrak{B}$ of the theory $T$, which omits $t_{\Sigma_{1}}^{\mathfrak{A}}(\bar{a})$. Let $f: \mathfrak{A} \rightarrow \mathfrak{B}$ be an embedding. Then by Lemma 4 we have $t_{\Sigma_{1}}^{\mathfrak{A}}(\bar{a}) \subseteq t_{\Sigma_{1}}^{\mathfrak{B}}(f(\bar{a}))$. It follows that $f(\bar{a})$ implements $t_{\Sigma_{1}}^{\mathfrak{A}}(\bar{a})$ to $\mathfrak{B}$. This contradicts Theorem 5 .

Definition 8. Let $t_{1}$ be the $\Gamma_{1}$-type, $t_{2}$ be the $\Gamma_{2}$-type, then they say that $t_{1}$ and $t_{2} T$-equivalent if $T \cup t_{1} \vdash t_{2}$ $\& T \cup t_{2} \vdash t_{1}$. In this case, write $t_{1} \sim_{T} t_{2}$. The following is known next lemma.

Lemma \%. Let $T$ be perfect Jonsson theory complete for $\Pi_{2}$ sentences and $\mathfrak{A} \models T$, then there is a model $\mathfrak{B}$, such that:

1) $\mathfrak{B} \models T$;

2) $\mathfrak{A}$ is isomorphically embeddable in $\mathfrak{B}$;

3) for any $\bar{b} \in B t_{\Sigma_{1}}^{\mathfrak{B}}(\bar{b}) \sim_{T} t_{\Sigma_{2}}^{\mathfrak{B}}(\bar{b})$.

Proof. The proof follows from [14] and the above definitions.

Theorem 8. Let $T$ be the perfect Jonsson theory complete for $\Pi_{2}$ sentences. Then every $(\Sigma, \Sigma)$-cl algebraically prime model of the theory $T$ is an almost-weakly $(\Sigma, \Sigma)$-cl atomic model of the theory $T$.

Proof. Firstly, we prove the following fact (F). If $\varphi(\bar{x}) \in \Sigma_{1}$ and $\varphi(\bar{x}) \cup T$ is consistent, then there is a formula $\psi(\bar{x}) \in \Sigma_{1}$ such that $T \cup \psi(\bar{x})$ is consistent and $T \models \psi(\bar{x}) \rightarrow \varphi(\bar{x})$. Indeed, let $\varphi(\bar{x}) \in \Sigma_{1}$ and $\varphi(\bar{x}) \cup T$ are consistent. Since that $T$ is complete for $\Pi_{2}$ sentences we have $T \vdash \exists \bar{x} \varphi(\bar{x})$. Since $T \Pi_{2}$ is axiomatizable, then by Lemma 7 there exists a model $\mathfrak{B}=T$, such that for any $\bar{b} \in B$ is holds

$$
t_{\Sigma_{1}}^{\mathfrak{B}}(\bar{b}) \sim_{T} t_{\Sigma_{2}}^{\mathfrak{B}}(\bar{b})
$$

Let $\bar{b} \in B$ such that $\mathfrak{B}=\varphi(\bar{b})$. Due to $\left(^{*}\right)$ and the closedness concerning the conjunction of the type $t_{\Sigma_{1}}^{\mathfrak{B}}(\bar{b})$ there is a formula $\psi(\bar{x}) \in t_{\Sigma_{1}}^{\mathfrak{B}}(\bar{b})$, such that $T \vdash \psi(\bar{x}) \rightarrow \varphi(\bar{x})$. Fact $(\mathrm{F})$ is proved.

Further $\mathfrak{A}$ be $(\Sigma, \Sigma)$-cl algebraically prime model of theory $T, \bar{a} \in A, t=t_{\Sigma}^{\mathfrak{A}}(\bar{a})$. By Theorem 6 A-almostweakly $(\Sigma, \Sigma)$-cl atomic model of theory $T$. Therefore, there is a formula $\varphi(\bar{x}) \in \Sigma$ consistent with $T$, which generates $t_{\Sigma}^{\mathfrak{A}}(\bar{a})$. According to $(\mathrm{F})$, there exists a formula $\psi(\bar{x}) \in \Sigma$ consistent with $T$, for which the following 
holds: $T \vdash \psi(\bar{x}) \rightarrow \varphi(\bar{x})$. Obviously $\psi(\bar{x})$ generates $t_{\Sigma}^{\mathfrak{A}}(\bar{a})$. Due to the arbitrariness $\bar{a} \in A$ a model $\mathfrak{A}$ is almostweakly $(\Sigma, \Sigma)$-cl atomic model of the theory $T$.

Remark. Let $\alpha, \beta \leq \omega, \bar{x}^{\alpha} \rightleftharpoons<x_{i}: 1 \leq i \leq 1+\alpha>, \bar{a}^{\alpha}=<a_{i}: 1 \leq i \leq 1+\alpha>$.

Definition 9. 1) $\alpha$-type is called any set of formulas consistent with $T$, the free variables of which are found in $\bar{x}$;

2) $\omega$-type $\rho$ is called $\Gamma$ - $\omega$-type, if $\rho \subseteq \Gamma$;

3) $\Gamma$ - $\omega$-type $\rho$ is called $\Gamma_{1}$-principle type if there exists such a sequence $\left\langle\psi_{n}\left(\bar{x}^{n}\right): 1 \leq n<\omega\right\rangle \Gamma_{1}$-formulas, such that:

a) $T \cup \psi_{n}\left(\bar{x}^{n}\right)$ is consistent, $1 \leq n<\omega$;

b) $\psi_{n}\left(\bar{x}^{n}\right)$ generates $\rho \uparrow \bar{x}^{n}$, where $\rho \uparrow \bar{x}^{n}$ is set of formulas from $\rho$, the free variables of which are among $\left(x_{1}, \ldots, x_{n}\right), 1 \leq n<\omega$;

c) $T \vdash \psi_{n}\left(\bar{x}^{n}\right) \leftrightarrow \exists \bar{x}_{n+1} \psi_{n+1}\left(\bar{x}^{n+1}\right), 1 \leq n<\omega$.

Definition 10. A model $\mathfrak{A}$ of the theory $T$ is said to be the fine almost-weakly $\left(\Gamma_{1}, \Gamma_{2}\right)$-cl atomic model of $T$ if each tuple of $\omega$ elements $\mathfrak{A}$ implements $\Gamma_{1}$-principle type $\Gamma_{2} \omega$-type.

Lemma 9. Let $\mathfrak{A}$ be a countable model of the perfect Jonsson theory $T, A=\bar{a}^{\omega}=<a_{1} \ldots, a_{n}, \ldots>$ implements $(\Sigma, \Sigma)$ - $\omega$-type. $\mathfrak{B} \models T, \mathfrak{B}$ is the isomorphically embeddable in $\mathfrak{A}$. Then $\mathfrak{B}$ is a fine almost-weakly $(\Sigma, \Sigma)$-cl atomic model of $T$.

Proof. Let $\bar{b}^{\omega}=<b_{1}, \ldots, b_{n}, \ldots>$ be an arbitrary tuple of $\omega$-elements $\mathfrak{B}$. Such that $\mathfrak{B}$ is the isomorphically embeddable in $\mathfrak{A}$, then $b_{k}=a_{i_{k}}$ for some $1 \leq k<\omega$.

Let $n_{k} \rightleftharpoons i j: 1 \leq j \leq k$,

$Z_{k}=1,2,3, . ., n_{k} \backslash i j: 1 \leq j \leq k ; \bar{y}^{k}=<y_{1}, \ldots, y_{k}>$.

Such that $\bar{a}^{\omega}$ implements the $\Sigma$-principal type $\Sigma$ - $\omega$-type, then there exists a sequence of $\Sigma$-formulas $\left\langle\psi_{n}\left(\bar{x}^{n}\right)\right.$ : $1 \leq n<\omega\rangle$, for which the following is true:

1) $\psi_{n}\left(\bar{x}^{n}\right) \cup T$ is consistent, $1 \leq n<\omega$;

2) $\psi_{n}\left(\bar{x}^{n}\right)$ generates $t_{\Sigma}^{\mathfrak{A}}\left(\bar{a}^{n}\right) 1 \leq n<\omega$;

3) $T \vdash \psi_{n}\left(\bar{x}^{n}\right) \leftrightarrow \exists \bar{x}^{n} \psi_{n+1}\left(\bar{x}^{n+1}\right) 1 \leq n<\omega$.

Let us denote by what

$$
S_{k}\left(\bar{y}^{k}\right) \rightleftharpoons\left\{\begin{array}{l}
\psi_{n_{k}}\left(\bar{x}^{n_{k}}\right)\left(\begin{array}{c}
x_{i 1}, \ldots, x_{i k} \\
y_{1}, \ldots, y_{k}
\end{array}\right), \text { if } Z_{k}=\emptyset \\
\exists \ldots x_{S} \ldots \psi_{n_{k}}\left(\bar{x}^{n_{k}}\right)_{S \in Z_{k}}\left(\begin{array}{c}
x_{i 1}, \ldots, x_{i k} \\
y_{1}, \ldots, y_{k}
\end{array}\right), \text { if } Z_{k} \neq \emptyset
\end{array}\right.
$$

Then it is clear that:

a) $S_{k}\left(\bar{y}^{k}\right) \in \Sigma_{1} 1 \leq k<\omega$;

b) $S\left(\bar{y}^{k}\right)$ consistent with $T, 1 \leq k<\omega$;

c) $S\left(\bar{y}^{k}\right)$ generates $t_{\Sigma_{1}}^{\mathfrak{A}}\left(\bar{b}^{k}\right), 1 \leq k<\omega$;

d) $T \vdash S_{k}\left(\bar{y}^{k}\right) \leftrightarrow \exists y_{k+1} S_{k+1}\left(\bar{y}^{k+1}\right), 1 \leq k<\omega$.

Further such that $\mathfrak{B}$ is isomorphic embedding $\mathfrak{A}$, then $t_{\Sigma}^{\mathfrak{B}}\left(\bar{b}^{k}\right) \subseteq t_{\Sigma}^{\mathfrak{A}}\left(\bar{a}^{k}\right)$. Hence $S\left(\bar{y}^{k}\right)$ generates $t_{\Sigma}^{\mathfrak{B}}\left(\bar{b}^{k}\right)$ $1 \leq k<\omega$. Thus, since $\bar{b}^{\omega}$ is arbitrary, the model $\mathfrak{B}$ is fine almost-weakly $(\Sigma, \Sigma)$-cl atomic model $T$.

Corollary 10. Let $\mathfrak{A}=T, \bar{a}^{\omega}=A$. Then:

1) if $\bar{a}^{\omega}$ implements $\Sigma$ is principle type $\Sigma$ - $\omega$-type, then any infinite $a^{\omega}$ implements some $\Sigma$-principle type $\Sigma$ - $\omega$-type;

$2)$ if $\mathfrak{A}$ is the fine an almost-weekly $(\Sigma, \Sigma)$-cl atomic model $T$, then $\mathfrak{A}$ is almost-weakly $(\Sigma, \Sigma)$-cl atomic model $T$.

Proof. Follows from Lemma 9.

Lemma 11. Let $T$ has a fine almost-weakly $(\Sigma, \Sigma)$-cl atomic model, then each $(\Sigma, \Sigma)$-cl algebraically prime model of theory $T$ is a fine almost-weekly $(\Sigma, \Sigma)$-cl atomic model of the theory $T$.

Proof. Let $\mathfrak{B}$ be an arbitrary $(\Sigma, \Sigma)$-cl algebraically prime model of theory $T, \mathfrak{A}$ is fine an almost-weekly $(\Sigma, \Sigma)$-cl atomic model of the theory $T$, then there is an embedding $f: \mathfrak{A} \rightarrow \mathfrak{B}$. Let $\mathfrak{A}^{\prime}=f[\mathfrak{B}]$. Obviously $\mathfrak{A}^{\prime}$ embedded in $\mathfrak{A}$, and by Lemma $9 \mathfrak{A}^{\prime}$, therefore $\mathfrak{B}$ is also fine almost-weakly $(\Sigma, \Sigma)$-cl-atomic models of the theory $T$.

Lemma 12. Let $T$ perfect Jonsson theory complete for $\Pi_{1}$-sentences. Then every fine almost-weakly $(\Sigma, \Sigma)$ $c l$-atomic models of the theory $T$ is a $(\Sigma, \Sigma)$-cl algebraically prime model of $T$. 
Proof. Let $\bar{a}^{\omega}=<a_{1}, \ldots, a_{n}, \ldots>$ are elements from $A$. Since $\bar{a}^{\omega}$ implements $\Sigma_{1}$-principal $\Sigma_{1}-\omega$-type, there exists $\left\langle\psi_{n}\left(\bar{x}^{n}\right): 1 \leq n<\omega\right\rangle$ - is a sequence of $\Sigma_{1}$-formulas for which the condition of item 3 of Definition 7 is true. Such that $T$ is complete for $\Pi_{1}$-sentences, then $\mathfrak{B}=\exists \bar{x}^{n} \psi_{n}\left(\bar{x}^{n}\right), 1 \leq n<\omega$, where $\mathfrak{B} \models T$. Further, since $T \vdash \psi_{n}\left(\bar{x}^{n}\right) \leftrightarrow \exists \bar{x}^{n+1} \psi_{n+1}\left(\bar{x}^{n+1}\right)$ for each $1 \leq n<\omega$, then it is possible (step by step) to gradually find such $b_{1}, \ldots, b_{n}$ from $B$, such that $\mathfrak{B} \models \psi_{n}\left(\bar{x}^{n}\right), 1 \leq n<\omega$, where $\bar{b}^{n}=\left\langle b_{1}, \ldots, b_{n}\right\rangle$. But $\psi_{n}\left(\bar{x}^{n}\right)$ generates $t_{\Sigma_{1}}^{\mathfrak{A}}\left(\bar{a}^{n}\right)$, so $t_{\Sigma_{1}}^{\mathfrak{A}}\left(\bar{a}^{n}\right) \subseteq t_{\Sigma_{1}}^{\mathfrak{B}}\left(\bar{b}^{n}\right), 1 \leq n<\omega$.

Therefore, the mapping $f: \mathfrak{A} \rightarrow \mathfrak{B}$, where $f\left(a_{n}\right)=b_{n}, 1 \leq n<\omega$, is an isomorphic embedding.

Theorem 13. Let $T$ be the perfect Jonsson theory complete for $\Pi_{1}$-sentences and has fine almost-weakly $(\Sigma, \Sigma)-c l$ atomic model. Then the following conditions are equivalent:

1) $\mathfrak{A}$ is the $(\Sigma, \Sigma)$-cl algebraically prime model of theory $T$.

2) $\mathfrak{A}$ is the fine almost-weakly $(\Sigma, \Sigma)$-cl atomic model of the theory $T$.

Proof. 1) $\Rightarrow$ 2) follows from Lemma 11. 2) $\Rightarrow$ 1) from Lemma 12.

\section{Acknowledgments}

This work was supported by the Science Committee of the Ministry of Education and Science of the Republic of Kazakhstan (grant AP09260237).

\section{References}

1 Vaught R. Denumerable models of complete theories in Infinitistic Methode / R. Vaught // Pergamon, London. - 1961. - P. 303-321.

2 Baldwin J.T. Algebraically prime models / J.T. Baldwin, D.W. Kueker // Ann. Math. Logic. - 1981. 20. - P. 289-330.

3 Yeshkeyev A.R. $\nabla$-cl-atomic and prime sets / A.R. Yeshkeyev, A.K. Issayeva // Bulletin of the Karaganda University. Mathematics series. - 2019. - 93. - No. 1. - P. 88-94. DOI 10.31489/2019 M1/88-94

4 Yeshkeyev A.R. The atomic definable subsets of semantic model / A.R. Yeshkeyev, A.K. Issayeva, N.M. Mussina // Bulletin of the Karaganda University. Mathematics series. - 2019. - 94. - No. 2. - P. 84-91. DOI 10.31489/2019M2/84-91

5 Yeshkeyev A.R. Closure of special atomic subsets of semantic model / A.R. Yeshkeyev, A.K. Issayeva, N.V. Popova // Bulletin of the Karaganda University. Mathematics series. - 2020. - 97. - No. 1. P. 97-103. DOI 10.31489/2020M1/97-103

6 Yeshkeyev A.R. Core Jonsson theories / A.R. Yeshkeyev, A.K. Issayeva, N.V. Popova // Bulletin of the Karaganda University. Mathematics series. - 2020. - 97. - No. 1. - P. 104-110. DOI 10.31489/2020M1 $/ 104-110$

7 Ешкеев А.Р. $\alpha$-алгебраические простые модели и виды атомных моделей теории / А.Р. Ешкеев, Т.Г. Мустафин // Теория алгебраических структур: сб. науч. тр. - Караганда, 1985. - С. 30-39.

8 Yeshkeyev A.R. Companions of the fragments in the Jonsson enrichment / A.R. Yeshkeyev // Bulletin of the Karaganda University. Mathematics series. - 2017. - 85. - No. 1. - P. 41-45. DOI 10.31489 $/ 2017 \mathrm{M} 1 / 41-45$

9 Yeshkeyev A.R. The Properties of Similarity for Jonsson's Theories and Their Models / A.R. Yeshkeyev // Bulletin of the Karaganda University. Mathematics series. - 2015. - 80. - No. 4. - P. 52-59.

10 Yeshkeyev A.R. Properties of hybrids of Jonsson theories / A.R. Yeshkeyev, N.M. Mussina // Bulletin of the Karaganda University. Mathematics series. - 2018. - 92. - No. 4. - P. 99-104. DOI 10.31489 /2018M4/99-104

11 Yeshkeyev A.R. Model-theoretical questions of the Jonsson spectrum / A.R. Yeshkeyev // Bulletin of the Karaganda University. Mathematics series. - 2020. - 98. - No. 2. - P. 165-173. DOI 10.31489 /2020M2/165-173

12 Yeshkeyev A.R. Method of the rheostat for studying properties of fragments of theoretical sets / A.R. Yeshkeyev // Bulletin of the Karaganda University. Mathematics series. - 2020. - 100. - No. 4. P. $152-159$. DOI $10.31489 / 2020 \mathrm{M} 4 / 152-159$

13 Ешкеев A.R. $J S p$-косемантичность $R$-модулей / A.R. Ешкеев, О.И. Ульбрихт // Сиб. электрон. мат. изв. $-2019 .-16$. - Р. 1233-1244. DOI 10.33048/semi.2019.16.084 
14 Chang C.C. Omitting tupes of prenex formulas / C.C. Chang // J. Sumb. Logic. - 1967. - 32. - No. 1. - P. 61-77.

15 Keisler H.J. Forsing and omitting tupes theorem / H.J. Keisler // Moscow. A.A. Studies. - 1973. - 8. - P. 96-133.

А.Р. Ешкеев, А.Қ. Исаева, Н.Қ. Шаматаева

Академик Е.А.Бөкетов атындавы Қараганды университеті, Қараванды, Қазақстан

\title{
Анықталған жиынының тұйықтау операторы көмегімен алынған атомдық және алгебралық жай модельдер туралы
}

\begin{abstract}
Мақалада қандай да бір бекітілген йонсондық теорияның семантикалық моделінің анықталған ішкі жиынында берілген қандайда бір тұйықтау операторының көмегімен алынған атомдық және жай модельдердің қасиеттері қарастырылған. Негізгі нәтиже ретінде атомдық және жай модельдерде анықталған эквиваленттілікті табу болып табылады, яғни бұл сәйкестік жақсы қасиеттерімен берілген қандай да бір модель бар деген шығады.
\end{abstract}

Kiлm сөздер: йонсондық теориясы, семантикалық модель, жай модель, атомдық модель, алгебралық жай модель, предгеометрия, анықталған ішкі жиын.

\author{
А.P. Ешкеев, А.К. Исаева, Н.К. Шаматаева
}

Карагандинский университет имени академика Е.А.Букетова, Караганда, Казахстан

\section{Об атомных и алгебраически простых моделях, полученных замыканием определимых множеств}

\begin{abstract}
В статье рассмотрены свойства атомных и простых моделей, полученных с помощью некоторого оператора замыкания, заданного на определимых подмножествах семантической модели некоторой фиксированной йонсоновской теории. Основным результатом явилось получение эквивалентности определенными таким образом атомной и простой моделей, причем это совпадение следует при предположении, что существует некоторая модель с хорошо заданными свойствами.
\end{abstract}

Ключевые слова: йонсоновская теория, семантическая модель, простая модель, атомная модель, алгебраически простая модель, предгеометрия, определимое подмножество.

\section{References}

1 Vaught, R. (1961). Denumerable models of complete theories in Infinitistic Methode. Pergamon, London, 303-321.

2 Baldwin, J.T., \& Kueker, D.W. (1981). Algebraically prime models. Ann. Math. Logic., 20, $289-330$.

3 Yeshkeyev, A.R., \& Issayeva, A.K. (2019). $\nabla$-cl-atomic and prime sets. Bulletin of the Karaganda University. Mathematics series, 93(1), 88-94. DOI 10.31489/2019M1/88-94

4 Yeshkeyev, A.R., Issayeva, A.K., \& Mussina, N.M. (2019). The atomic definable subsets of semantic model. Bulletin of the Karaganda University. Mathematics series, 94(2), 84-91. DOI 10.31489/2019M2/84-91

5 Yeshkeyev, A.R., Issayeva, A.K., \& Popova, N.V. (2020). Closure of special atomic subsets of semantic model. Bulletin of the Karaganda University. Mathematics series, 97(1), 97-103. DOI 10.31489/2020M1 $/ 97-103$ 
6 Yeshkeyev, A.R., Issayeva, A.K., \& Popova, N.V. (2020). Core Jonsson theories. Bulletin of the Karaganda University. Mathematics series, 97(1), 104-110. DOI 10.31489/2020M1/104-110

7 Yeshkeyev, A.R., \& Mustafin, T.G. (1985). $\alpha$-algebraicheskie prostye modeli i vidy atomnykh modelei teorii [ $\alpha$-algebraically prime models and types of atomic theory models.] Teoriia algebraicheskikh struktur: sbornik nachnykh trudov, 30-39 [in Russian].

8 Yeshkeyev, A.R. (2017). Companions of the fragments in the Jonsson enrichment. Bulletin of the Karaganda University. Mathematics series, 85(1), 41-45. DOI 10.31489/2017M1/41-45

9 Yeshkeyev, A.R. (2015). The Properties of Similarity for Jonsson's Theories and Their Models. Bulletin of the Karaganda University. Mathematics series, 80(4), 52-59.

10 Yeshkeyev, A.R., \& Mussina, N.M (2018). Properties of hybrids of Jonsson theories. Bulletin of the Karaganda University. Mathematics series, 92(4), 99-104. DOI 10.31489/2018M4/99-104

11 Yeshkeyev, A.R. (2020). Model-theoretical questions of the Jonsson spectrum. Bulletin of the Karaganda University. Mathematics series, 98(2), 165-173. DOI 10.31489/2020M2/165-173

12 Yeshkeyev, A.R. (2020). Method of the rheostat for studying properties of fragments of theoretical sets. Bulletin of the Karaganda University. Mathematics series, $100(4), 152-159$. DOI 10.31489/2020M4/152159

13 Yeshkeyev, A.R., \& Ulbrikht, O.I. (2019). JSp-kosemantichnost $R$-modulei [JSp-cosemanticness of $R$-modules]. Sibirskie electronnye matematicheskie izvestia - Siberian electronic mathematical reports, 16 , 1233-1244. DOI 10.33048/ semi.2019.16.084 [in Russian]

14 Chang, C.C. (1967). Omitting tupes of prenex formulas. J. Sumb. Logic, 32(1), 61-77.

15 Keisler, H.J. (1973). Forsing and omitting tupes theorem. Moscow. A.A. Studies, 8, 96-133. 